\title{
Global Yerpotansiyel Modellerin Gravimetrik Jeoit Belirlemeye Katkısı
}

\author{
Selda DEMIR ${ }^{1}$, R. Alpay ABBAK ${ }^{2 *}, H$. Tuğba ARLI IL ${ }^{3}$ \\ ${ }^{1}$ Gaziosmanpaşa Üniversitesi, Tokat Teknik Bilimler MYO, Tokat \\ (selda.demir@gop.edu.tr) ORCID ID0000-0003-3551-3562 \\ ${ }^{2}$ Selçuk Üniversitesi, Harita Mühendisliği Bölümü, Konya \\ (aabbak@selcuk.edu.tr) ORCID ID0000-0002-6944-5329 \\ ${ }^{3}$ T.C. Sağlık Bakanlığı, , Sağlık Yatırımları Genel Müdürlüğü, Ankara \\ (arlihtuba@gmail.com) ORCID ID0000-0002-7186-3685
}

\begin{abstract}
Öz
Gravimetrik jeoit belirlemede global yerpotansiyel modellerinden, sayısal yükseklik modellerinden ve yersel gravite gözlemlerinden yararlanılır. Yeryuvarının tümüne homojen olarak yayılmış gravite gözlemlerinin değerlendirilmesiyle global yerpotansiyel modeller üretilir. Global yerpotansiyel modellerin doğruluğu, bu modeller kullanılarak oluşturulacak çalışmaların başarısını doğrudan etkileyecektir. Bu uygulamada yakın tarihlerde CHAMP, GRACE ve GOCE uydu verileri yardımıyla oluşturulan yeni nesil global yerpotansiyel modellerinden türetilen jeoit ondülasyonları, GPS/Nivelman verilerinden elde edilen eşlenikleri ile karşılaştırılıp seçilen güncel global yerpotansiyel modellerinin doğrulukları bölgesel olarak değerlendirilmiştir. Ele alınan yeni nesil global yerpotansiyel modeller kullanılarak KTH tekniği ile Konya Kapalı Havzasında 12 adet gravimetrik jeoit modeli oluşturulmuş ve oluşturulan her bir model 7 parametreli benzerlik dönüşümü yardımıyla GPS/Nivelman verileri kullanılarak karşılaştırılmıştır. Sonuç olarak yeni nesil global yerpotansiyel modelinin doğruluğunun hesaplanan gravimetrik jeoit modelinin doğruluğuna yaptığı katkılar sayısal anlamda ortaya konmuştur.
\end{abstract}

Anahtar Kelimeler: Gravimetrik jeoit belirleme, global yerpotansiyel modeller, Konya Havzasl, KTH tekniği,

\section{Contribution of Global Geopotential Models to Gravimetric Geoid Determination}

\begin{abstract}
Global geopotential models, digital elevation models and local gravity observations are utilized in the gravimetric geoid determination. By assessing gravitational observations homogeneously distributed throughout the earth, global geopotential models are produced. The validity of the global geopotential models will directly affect the success of the studies to be done through these models. In this study, geoid undulations derived from the new generation global geopotential models yielded by the data of CHAMP, GRACE and GOCE satellites in recent years are compared with the equivalents obtained from GPS/leveling data and the validity of selected current global geopotential models are evaluated regionally. Twelve gravimetric geoid models have been created in Konya Closed Basin through KTH technique by using the new generation global geopotential model, and using GPS/Leveling data through 7-parameter similarity transformation compared each geoid model. As a result, the contributions of the new generation global geopotential model to the accuracy of gravimetric geoid model are presented numerically.
\end{abstract}

Keywords: Gravimetric geoid detemination, global geopotential models, Konya Basin, KTH technique

\footnotetext{
* Sorumlu yazar
} 


\section{GÍRIŞ}

Jeoit, ortalama deniz düzeyiyle çakışan, her noktasında çekül doğrultusuna dik olan kapalı bir yüzeydir. Yer bilimleri açısından jeoidi belirlemek oldukça önemlidir. Çünkü yeryüzündeki noktaların ortometrik yüksekliği referans kabul edilen jeoitten itibaren ölçülür. Yani yükseklik ve derinlik kavramları jeoit ile tanımlıdır.

Jeoit belirleme yöntemleri kullanılan veri gruplarına göre gravimetrik, astro-jeodezik ve geometrik olmak üzere üç sınıfta ele alınır (Abbak, 2017). Gravimetrik yöntemde yersel ve uzaysal gravite verileri analiz edilerek jeoit belirlenir. Yeryuvarının gravite alanı bilgisini elde etmek için farklı ölçme yöntemleri ve çözüm teknikleri geliştirilmiştir. Yeryüzünün gravite alanı global olarak uydular yardımıyla (CHAMP, GRACE, GOCE), bölgesel olarak uçaktan, denizden gravite ölçüleriyle ve yersel gravite ölçüleriyle belirlenir. Yeryuvarının tümüne homojen olarak yayılmış gravite gözlemlerinin değerlendirilmesiyle global yerpotansiyel modeller üretilir. Literatüre bakıldığından 160'den fazla global yerpotansiyel modelin olduğu görülmektedir (ICGEM, 2018).

$\mathrm{Bu}$ çalışmada bölgesel gravimetrik jeoit belirlemek için KTH (Kungliga Tekniska Högskolan) tekniği kullanılmıştır. KTH tekniğinden yararlanarak jeoit belirlemek için global yerpotansiyel modeli, yersel gravite verileri ve sayısal yükseklik modeli olmak üzere 3 çeşit veriye ihtiyaç vardır. Bundan dolayı bu çalışmada; CHAMP, GRACE ve GOCE uydularından elde edilen global yerpotansiyel modellerinden en az ikişer adet güncel model seçilmiştir. Çalışmada değerlendirilecek yersel gravite gözlemleri Abbak (2011) tarafından gerçekleştirilen proje kapsamında Harita Genel Komutanlığı'ndan elde edilmiştir. Konya Kapalı Havzasında oluşturulacak bölgesel jeoit için toplamda 3073 gravite noktas1 mevcuttur. Sayısal yükseklik modeli olarak ise SRTM (SRTM, 2018) seçilmiştir. Seçilen yeni nesil global yerpotansiyel modellerin bölgesel analizinde ve oluşturulan bölgesel jeoit modellerinin bölgesel doğruluklarını incelemek amacıyla proje alanında ortometrik yükseklikleri de bilinen toplam 24 adet GPS/Nivelman noktas1 kullanılmıştır.
Bölgesel jeoit belirleme işlemine başlamadan önce ilk aşamada seçilen global yerpotansiyel modeller Konya Kapalı Havzasinda bulunan GPS/Nivelman verileri yardımıyla bölgesel doğrulukları incelenmiştir. Böylelikle global olarak gravite alanı belirleme amaçlı kullanılan yakın yer uydularının gelişmelerini gözlemlemek ve başarı oranını belirlemek amaçlanmıştır. Seçilen global yerpotansiyel modellerinden türetilen jeoit ondülasyonları, GPS/Nivelman verilerinden elde edilen eşlenikleri ile 7 parametreli benzerlik dönüşümü kullanılarak karşılaştırılmıştır. Karşılaştırmaya göre GOCE ve GRACE uydu verilerinin birlikte değerlendirilmesi ile oluşturulan ITU_GGC16 (Akyılmaz vd 2016) modeli en başarılı model olarak belirlenmiştir. Sadece GOCE uydu verileri ile elde edilen modellerin başarılı sayılabileceği ancak GRACE uydu verilenin de çözüme dahil edilmesiyle azda olsa modellerin doğruluğunun arttırılabildiği görülmüsştür.

İkinci aşamada ise seçilen herbir global yerpotansiyel modeli kullanılarak KTH tekniği ile Konya Kapalı Havzası'nda toplam 12 adet bölgesel gravimetrik jeoit modeli oluşturulmuştur. Seçilen global yerpotansiyel modelinin doğruluğunun hesaplanan gravimetrik jeoit modelinin doğruluğuna yaptığı katkıları belirlemek amaciyla yine GPS/Nivelman verileri yardımıyla 7 parametreli benzerlik dönüşümü kullanılarak karşılaştırılmıştır. Karşılaştırmaya göre jeoit yüzeyi belirlerken doğruluğu değiştiren ve etkileyen asıl faktörün yersel gravite verilerinin kalitesi olduğu gösterilmiştir.

Literatüre bakıldığında global yerpotansiyel modellerin gravimetrik jeoit belirlemeye etkisini inceleyen çalışmalardan bazıları; Kiamehr (2006), Ulotu (2009), Erol ve diğ. (2009), Abbak (2011), Al-Krargy ve diğ. (2015), Doğanalp (2016)'dır. Yapılan bu çalışmalarda gravimetrik jeoit oluşturma ve global yerpotansiyel modellerin gravimetrik jeoit belirlemeye katkısı hakkında detaylı bilgiler elde edinilmiştir. Bu çalışmada ise IfE_GOCE05s (Wu vd. 2017), TongjiGrace02s (Chen vd 2016), ITU_GGC16 (Aky1lmaz vd 2016) gibi sadece yakın yer uydu verilerinden hesaplanan en güncel 12 adet yerpotansiyel modelin bölgesel doğrulukları mutlak anlamda incelenmiştir. Sonrasında her bir model bölgesel jeoit 
modellerinin hesaplanmasinda referans model olarak kullanılarak güncel yerpotansiyel modellerin bölgesel jeoide etkisi ortaya konulmuştur.

\section{YÖNTEM}

\subsection{Mutlak Değerlendirme}

Global konumlama sistemi GPS ile duyarlı bir şekilde üç boyutlu konum belirlenmektedir. GPS ile elde edilen veriler yermerkezli bir koordinat sisteminde coğrafi enlem $(\varphi)$, coğrafi boylam $(\lambda)$ ve elipsoidal yükseklikler (h) olarak hesaplanır. Elipsoidal yükseklikler gerçek yükseklikleri yani ortalama deniz seviyesinden olan yükseklikleri temsil etmezler.

Ortometrik yükseklik $H$, noktanın bulunduğu fiziksel yeryüzünden jeoide kadar çekül eğrisi boyunca olan uzunluğudur. Deniz noktasının sıfır olarak kabul edildiği bir noktadan başlayıp, geometrik nivelman ile ortometrik yükseklikler bulunur. $\mathrm{Bu}$ iki yükseklik arasındaki fark1 jeoit ondülasyonu olarak bilinir ve,

$N_{\text {Geometrik }} \approx h-H$

eşitliğiyle hesaplanır.

Gravimetrik yöntemle belirlenen değerler ile GPS/Nivelman yöntemi ile bulunan değerler birlikte değerlendirilebilir (Erol vd 2008). Böylelikle gravimetrik jeoidin barındırdığ 1 sistematik hatalar giderilir. $\mathrm{Bu}$ işlem yapilırken GPS ile elde edilen konumlardaki $N_{\text {Geometrik }}$ değerleri enterpolasyon ile Gravimetrik jeoitte bulunan $N_{\text {Gravimetrik }}$ konumlarına taşınmalıdır. Sonuç olarak aynı konumda $N_{\text {Geometrik }}$ ve $N_{\text {Gravimetrik }}$ değerleri elde edilir. İki değer de birbirinden farklı datumlara sahip ise doğrudan karşılaştırma yapilamaz. Ortalama bir fark;

$\Delta N=N_{\text {Gravimetrik }}-N_{\text {Geometrik }}=\mathbf{A}^{\mathrm{T}} \mathbf{x}+\varepsilon$

eşitliğiyle ifade edilir. Burada A katsayılar matrisi, $\mathbf{x}$ bilinmeyenler vektörü, $\varepsilon$ rastgele hata terimidir. Düzeltici yüzey (corrector surface) olarak tanımlanan bu yüzey modelinin gravimetrik ve GPS/Nivelman jeoitleri arasındaki tüm sistematik hataları elemine ettiği varsayılır. Gravimetrik jeoidi ulusal datuma uydurmak için kullanılan bu yüzey genellikle 4,5 ve 7 parametreli benzerlik dönüşüm modelleri ile ifade edilir
(Abbak, 2017). Dört parametreli dönüşüm bir ölçek faktörü, bir yönlü dönüklük, iki öteleme; beş parametreli dönüşüm bir ölçek faktörü, iki yönlü dönüklük, iki öteleme; yedi parametreli dönüşüm bir ölçek faktörü, üç yönlü dönüklük, üç öteleme barındırmaktadır. Çalışmada daha güvenilir sonuçlar verdiğinden yedi parametreli dönüşüm tercih edilmiştir.

$a=\left[\begin{array}{c}\cos \varphi_{i} \cos \lambda_{i} \\ \cos \varphi_{i} \sin \varphi_{i} \\ \sin \varphi_{i} \\ \cos \varphi_{i} \sin \varphi_{i} \cos \lambda_{i} / W_{i} \\ \cos \varphi_{i} \sin \varphi_{i} \cos \lambda_{i} / W_{i} \\ \sin ^{2} \varphi_{i} / W_{i} \\ 1\end{array}\right]$

eşitliğinde $\varphi_{i}$ ve $\lambda_{i}$, GPS noktasının coğrafi koordinatlarını ifade ederken, $W_{i}$ katsayıs1;

$W_{i}=\sqrt{1-e^{2} \sin ^{2} \varphi_{i}}$

ile ifade edilir. $e^{2}$ referans elipsoidinin birinci dışmerkezliğinin karesidir.

Her bir GPS noktasında hesaplan a katsayılar vektörü genişletilerek A katsayılar matrisi elde edilir. En küçük kareler ile denklem çözümünden;

$\mathbf{x}=\left(\mathbf{A}^{\mathrm{T}} \mathbf{A}\right)^{-\mathbf{1}} \mathbf{A}^{\mathrm{T}} \mathbf{l}$

bilinmeyen parametreler vektörü hesaplanır. I gravimetrik ve geometrik jeoit yükseklikleri arasındaki fark yani küçültülmüş ölçü vektörüdür. Ölçülere getirilecek düzeltme değerleri;

$\mathbf{v}=\mathbf{A x}-\mathbf{l}$

vektörü ile belirlenirken standart sapması;

$m_{0}=\sqrt{\frac{v^{T} v}{n-u}}$

eşitlikleriyle belirlenir. Denklemlerde $n$ GPS/Nivelman nokta sayısinı, $u$ parametre sayısını (örn. $4,5,7$ ) temsil eder.

\subsection{KTH Tekniği}

KTH tekniğinde, boşlukta gravite anomalisi jeoit ondülasyon hesabında doğrudan yer almaktadır. Ancak bu gravite anomalisi türü topografya ile yüksek korelasyonludur. Bu durumda dağınık halde bulunan nokta gravite değerleri daha yumuşak bir yüzeyi temsil eden Bouguer yaklaşımı ile grid merkezlerine taşınmalıdır. Bu işlem için, rastgele dağılmış gravite noktalarında gravite değerleri, 
Bouguer anomalilerine indirgenir. Bjerhammer kuralına uygun olarak en yakın komşuluk enterpolasyon yöntemi ile Bouguer anomalileri grid merkezlerine taşınır. Bouguer anomalilerinden, gridlerin Bouguer plakas1 etkisi geri çıkarıldığında boşlukta gravite anomalilerine geçiş yapılır. Bu hesaplama için Bouguer plaka etkisi her grid için sayısal yükseklik modelinden elde edilen ortalama grid yüksekliğinden hesaplanabilir. Böylece jeoit modelleme için temel veri grubu olan gravite anomalileri grid halinde elde edilir. Gravite verileri hazırlandıktan sonra jeoit ondülasyonunun hesabına geçilir.

\subsubsection{Stokes integrali}

G. G. Stokes 1849 yılında kendi adıyla adlandırılan Stokes integral eşitliğini yayınlayarak, jeoit ondülasyonunun bu eşitlikle hesaplanabileceğini ortaya koymuştur. Jeoit ondülasyonu,

$N=\frac{R}{4 \pi \gamma} \iint_{\sigma} S(\psi) \Delta g d \sigma$

eşitliğiyle hesaplanır (Heiskanen ve Moritz, 1967). Bu eşitlikte; $R$ ortalama yer yarıçapını, $\gamma$ referans elipsoidi yüzeyindeki normal gravite değerini, $\psi$ yermerkezli açıyı, $\Delta g$ gravite anomalisini, d $\sigma$ birim küre $\sigma$ 'nın en küçük yüzey elemanını, $S(\psi)$ Stokes fonksiyonunu ifade etmektedir. Stokes fonksiyonu;

$S(\psi)=\sum_{n=2}^{\infty} \frac{2 n+1}{n-1} P_{n}(\cos \psi)$

küre üzerinde $n$ küresel harmonik dereceli Legendre polinomlariyla $P_{n}(\cos \psi)$ tanımlanan fonksiyondur (Heiskanen ve Moritz, 1967). Jeoidi belirleme amaçlı bu yüzey integralin çalışması için tüm yeryuvarına ait gravite verilerine ihtiyaç vardır. Ancak bu veri yığınıyla çalışmak olanaksızdır. Bu nedenle eşitlik istenilen bölgede sınırlandırılıp yeniden düzenlenerek kullanılır. Sınırlandırma işlemi sonucunda $\sigma_{0}$ çalışma bölgesinde kesilen integral;

$N^{L}=\frac{R}{4 \pi \gamma} \iint_{\sigma_{0}} S^{L}(\psi) \Delta g d \sigma$

şeklinde oluşur. Ancak uzak nokta etkisinin göz önüne alınmamasından dolayı kesme hatas1 (truncation error) olarak adlandırılan hata ortaya çıkar ve

$\delta N=N-N^{L}$

eşitliğiyle gösterilir.
Günümüzde yapay uydular yardımıyla gravite alanının uzun dalga boylu bileşenleri yerpotansiyel modellerin içinde yüksek doğrulukla yer almaktadır. Daha önceden yapılmış olan çalışmalar incelendiğinde global yerpotansiyel modellerden türetilen uzun dalga boylu bileşenler hesaplamaya dahil edildiğinde uzak bölgelerden kaynaklanan kesme hatasının en az düzeye indirilebileceği ortaya çıkmıştır.

\subsubsection{Stokes integralinin modifikasyonu}

Stokes integalini yeniden düzenleme yöntemleri deterministik ve stokastik olarak iki grupta incelenmektedir. Deterministik yöntem sadece kesme hatasinı en aza indirgemeyi amaçlarken, stokastik yöntem kesme hatasiyla birlikte yersel verilerden ve global yerpotansiyel modellerden kaynaklı hataları en aza indirmeyi amaçlamıştır. $\mathrm{Bu}$ sebeple bu çalışmada en küçük kareler prensibi ile daha geniş kapsamlı hatayı en aza indirgemeyi amaçlayan stokastik yöntem olan KTH tekniği tercih edilmiştir. KTH tekniğinde yaklaşık jeoit ondülasyonu;

$\widetilde{N}=\frac{R}{4 \pi \gamma} \iint_{\sigma_{0}} S^{L}(\psi) \Delta g d \sigma+\frac{R}{2 \gamma} \sum_{n=2}^{M} b_{n} \Delta g_{n}^{G G M}(12)$ ile hesaplanır (Sjöberg, 2003b). Burada $S^{L}(\psi)$ yerel Stokes fonksiyonunu, $M$ yerpotansiyel modelin kullanılan en büyük açınım derecesini, $\quad \gamma$ elipsoit üzerinde normal graviteyi, $b_{n} \mathrm{KTH}$ modifikasyon parametresini temsil eder. Eşitlikte görüldügü üzere, gravite anomalisinin doğruluğu, yaklaşık jeoit ondülasyonunun doğruluğuna doğrudan etki yapacaktır. Diğer yandan, KTH yöntemi yaklaşık ondülasyonlara bazı düzeltmeler yaparak kesin ondülasyon değerine ulaşır.

\subsection{Düzeltmeler}

KTH yöntemi ile ondülasyon değerleri hesaplanırken yeryuvarı dışında kitle olmadığ 1 varsayımı gibi bazı kabuller yapılır. Kesin sonuçları bulmak amacıyla birtakım düzeltmeler yapılmalıdır. Kaldır-HesaplaYerine Koy (Remove-Compute-Restore) gibi farklı diğer yöntemlerde düzeltmeler doğrudan gravite anomalilerine yapılmaktadır. Ancak KTH yönteminde düzeltmeler hesap kolaylığından dolayı yaklaşık ondülasyonlara yapılır. KTH yöntemine göre jeoit ondülasyonunun kesin değeri; 


$$
\widehat{N}=\widetilde{N}+\delta N_{\text {comb }}^{\mathrm{Top}}+\delta N_{\text {comb }}^{\mathrm{Atm}}+\delta N^{\mathrm{DWC}}+\delta N^{\mathrm{Ell}}
$$

eşitliğiyle hesaplanır (Sjöberg, 2003a). Eşitlikteki $\delta N_{\text {comb }}^{\text {Top }}$ kombine topografik düzeltmeyi, $\delta N_{\text {comb }}^{\text {Atm }}$ kombine atmosferik düzeltmeyi, $\delta N^{\text {DWC }}$ indirgeme düzeltmesini (downward continuation), $\delta N^{\text {Ell }}$ ise elipsoidal düzeltmeyi temsil etmektedir.

KTH metodunda yeryuvarı dışında kitle olmadığı varsayımı yapılır ve bu kabulden kaynaklanan hatanın etkisini gidermek için topografik düzeltme yapılır. Düzeltme direkt ve dolaylı etkilerin birleşiminden ortaya çıktığı için kombine topografik düzenleme olarak adlandırılır. Bu düzeltmenin hesabı;

$\delta N_{\text {comb }}^{\text {Top }}=\delta N_{\text {dir }}^{\text {Top }}+\delta N_{\text {ind }}^{\text {Top }}=-\frac{2 \pi G \rho}{\gamma} \sum_{n=2}^{\infty} H_{n}^{2}(14)$

formülüyle yapılır. Burada $\rho\left(2.67 \mathrm{~g} / \mathrm{cm}^{3}\right)$ yerkabuğunun yoğunluğunu, $G$ evrensel çekim sabitini, $H$ grid merkezinin ortalama yüksekliğini temsil etmektedir. Grid merkezinin ortalama yüksekliği $H$ değeri topografyanın sayısal yükseklik modelinden yararlanarak elde edilmesi gerekmektedir. Yerkabuğunun yoğunluğu $\rho$, topografik düzeltmeyi doğrudan etkiler.

Jeoit yüzeyi dışında kalan atmosferin etkisi yok sayılamayacağından dolayı bir düzeltme terimi olarak ondülasyon hesabında bulunmalıdır. Atmosferik düzeltme terimi;

$\delta N_{\mathrm{comb}}^{\mathrm{Atm}}=-\frac{G R \rho^{a}}{\gamma} \iint_{\rho^{a}} S^{L}(\psi) H_{p} d \sigma$

şeklinde hesaplanabilir. Burada $\rho^{a}$ deniz düzeyindeki atmosfer yoğunluğu (1.23 $\left.\mathrm{kg} / \mathrm{m}^{3}\right), \quad H_{p}$ hesap noktasinın topografik yüksekliğini gösterir ki bu değer sayısal yükseklik modelinden türetilen ortalama yüksekliktir.

Yersel gravite verileri jeoit belirleme işlemlerinde öncelikle deniz düzeyine indirgenerek hesaba dahil edilmelidir. Jeoit yüzeyi ile fiziksel yeryüzü arasındaki düzensiz kitle dağılımından dolayı gravite anomalisi, yüksekliğe göre doğrusal bir değişim göstermez. $\mathrm{Bu}$ sebeple $\mathrm{KTH}$ tekniğinde indirgeme düzeltmesi;

$\delta N^{\mathrm{DWC}}=\delta N_{\mathrm{dwc}}^{(1)}+\delta N_{\mathrm{dwc}}^{L 1, \mathrm{Far}}+\delta N_{\mathrm{dwc}}^{L 2}$

üç bileşenden oluşur (Sjöberg, 2003c). Bu bileşenler,

$$
\begin{aligned}
& \delta N_{\mathrm{dwc}}^{(1)}=\frac{\Delta g}{\gamma} H_{P}+3 \frac{\widetilde{N}}{r_{P}} H_{P}-\left.\frac{1}{2 \gamma} \frac{\partial \Delta g}{\partial r}\right|_{P} H_{P}^{2} \\
& \delta N_{\mathrm{dwc}}^{L 1, \mathrm{Far}}=\frac{R}{2 \gamma} \sum_{n=2}^{M} b_{n}\left[\left(\frac{R}{r_{P}}\right)^{n+2}-1\right] \Delta g_{n} \\
& (18) \\
& \delta N_{\mathrm{dwc}}^{L 2}=\frac{R}{4 \gamma \pi} \iint_{\sigma_{0}} S^{L}(\psi)\left(\left.\frac{\partial \Delta g}{\partial r}\right|_{P}\left(H_{P}-H_{Q}\right)\right) d \sigma_{Q}
\end{aligned}
$$

şeklinde sıralanır. Burada $r_{P} \mathrm{P}$ noktasının küresel yarıçapını, $H_{P}$ hesap noktasının topografik yüksekliğini temsil eder.

Stokes yaklaşımı $R$ yarıçaplı küre üzerinde uygulanır. Bu sebeple jeoit ondülasyonlarına elipsoidal düzeltmede getirilmelidir. Hesaplamalara getirilecek elipsoidal düzeltme;

$$
\begin{aligned}
& \delta N^{\text {Ell }}=\left[\left(0.0036-0.0109 \sin ^{2} \varphi\right) \Delta g+\right. \\
& \left.0.0050 \widetilde{N} \cos ^{2} \varphi\right] Q_{0}^{L}
\end{aligned}
$$

eşitliğiyle hesaplanır (Ellmann ve Sjöberg, 2004). Eşitlikte geçen $\Delta g$ yersel gravite anomalisi, $\widetilde{N}$ yaklaşık jeoit ondülasyonu, $Q_{0}^{L}$ Molodensky kesme katsayısıdır.

\subsection{Veri toplama}

$\mathrm{Bu}$ bölümde çalışma alanı ve sayısal uygulamada kullanılan veriler hakkında bilgi verilmiştir.

\subsection{1. Çalış̧ma alanı}

Sayısal uygulamada $37^{\circ} \leq \varphi \leq 39^{\circ}$ kuzey enlemleri, $31.5^{\circ} \leq \lambda \leq 35.0^{\circ}$ doğu boylamları arasında kalan Konya Kapalı Havzası seçilmiştir (Şekil 1). Çalışma alanının güneyinde Toros Dağları, kuzeyinde Tuz Gölü bulunmaktadır ve Konya, Karaman, Aksaray ve Niğde illerini kapsamaktadır. Çalışma alanı toplam $70000 \mathrm{~km}^{2}$ 'dir.

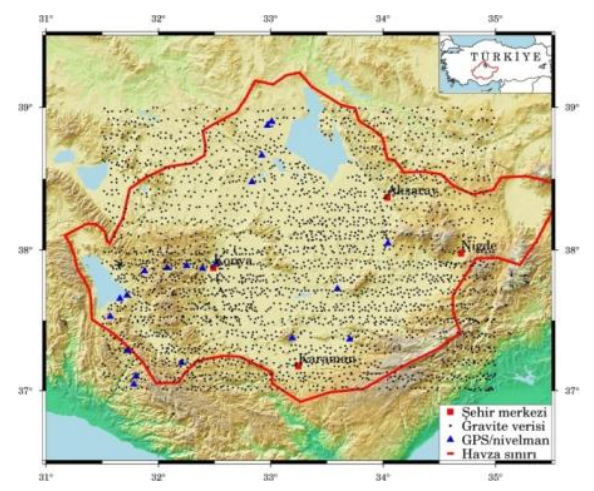

Şekil 1. Çalışma alanının topografik durumu ve mevcut verilerin dağılımı (Abbak, 2011) 
Topografik durum incelendiğinde, Toros Dağlarında en fazla yükseklik (max: $3491 \mathrm{~m}$ ) görülmekle birlikte çalıșma alanının güneyinde bulunan Göksu Vadisinde en düşük yükseklik (min: $576 \mathrm{~m}$ ) bulunmaktadır. Çalışma alanında ortalama yükseklik 1250 m'dir.

\subsubsection{Gravite verileri}

Çalı̧̧mada değerlendirilecek gravite gözlemleri Abbak (2011) tarafindan gerçekleştirilen proje kapsamında Harita Genel Komutanlığı'ndan elde edilmiştir. Gravite değerleri International Gravity Standardization Net 71 (IGSN71) datumundadır. Coğrafi koordinatlar World Geodetic System 1984 (WGS84) datumundadır. Her nokta için gravite bilgisi sırasıyla, gravite noktasının enlemi, boylamı, ortometrik yüksekliği (ortalama deniz yüzeyinden) ve gravite değeridir. Gravite verilerinin coğrafi dağılımı Şekil 1'de gösterilmiştir. Toplam gravite nokta sayısı 3073'tür.

Gravite verilerinin doğruluğu ve sıklığ 1 hesaplanacak bölgesel jeoidin hassasiyetini doğrudan etkileyecektir. Gravite verilerinin dağılımına bakıldığında, gravite ölçüsü bulunmayan açıklıklar ve seyrek ölçülmüş bölgeler bulunmaktadır. Ayrıca gravite verilerinin yoğunluğu çalışma sahası göz önüne alındığında genel olarak yeterli sıklıkta değildir. Son olarak bölgesel jeoit hesaplamalarında hesap noktasi etrafinda en

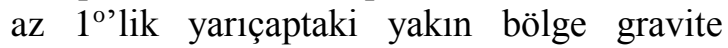
verileri gerekmektedir. Bu çalışmada yakın bölge gravite verileri ekonomik sebeplerden dolay1 elde edilememiştir.

\subsubsection{Global yerpotansiyel modelleri}

Jeodezik amaçlar doğrultusunda CHAMP, GRACE ve GOCE gibi alçak yörüngeli uydular yardımıyla yeryuvarı gravite alanı bilgilerinden elde edilen global yerpotansiyel modelleri ICGEM web sayfasinda yayınlanmaktadır (CHAMP, 2018; GRACE, 2018; GOCE, 2018). ICGEM web sayfasında günümüze kadar oluşturulmuş 160 'dan fazla global yerpotansiyel modeli mevcuttur (ICGEM, 2018).

Global modeller sürekli uydu verilerini içerdiğinden son yayınlananların yerin gravite alanını daha gerçekçi yansıtması kaçınılmazdır. Bu çalışma için seçilen güncel global yerpotansiyel modelleri hakkında bilgiler Tablo 1'de verilmiştir.

Tablo 1. Test için seçilen yeni nesil global yerpotansiyel modeller

\begin{tabular}{lccll}
\hline Model Ad1 & Y11 & Derece & Veri Kaynağ 1 & Referans \\
\hline EIGEN-CHAMP05S & 2010 & 150 & S (Champ) & Flechtner et al, 2010 \\
ULux_CHAMP2013s & 2013 & 120 & S (Champ) & Weigelt et al, 2013 \\
GOCO01S & 2010 & 224 & S (Champ, Grace) & Pail et al, 2010 \\
HUST-Grace2016s & 2016 & 160 & S (Grace) & Zhou et al, 2016 \\
Tongji-GRACE01 & 2013 & 160 & S (Grace) & Shen et al, 2013 \\
ITG-Grace2010s & 2010 & 180 & S (Grace) & Mayer-Gürr et al, 2010 \\
Tongji-Grace02s & 2017 & 180 & S (Grace) & Chen et al, 2016 \\
JYY_GOCE04S & 2014 & 230 & S (Goce) & Yi et al, 2013 \\
GO_CONS_GCF_2_SPW_R4 & 2014 & 280 & S (Goce) & Gatti et al, 2014 \\
IIfE_GOCE05s & 2017 & 250 & S (Goce) & Wu et al, 2017 \\
GGM05G & 2015 & 240 & S (Grace,Goce) & Bettadpur et al, 2015 \\
ITU_GGC16 & 2016 & 280 & S (Grace,Goce) & Akyilmaz et al, 2016 \\
\hline
\end{tabular}

Modeller seçilirken üretim yılı, veri kaynağ ve küresel harmonik açınımının derecesi dikkate alınmıştır. Böylece gravite alanı belirleme amaçlı tüm uydu çalışmalarının performansların analiz etmek ve zaman içerisindeki gelişimini irdelemek hedeflanmiştir. 


\subsubsection{Sayısal Yükseklik modeli}

Sayısal yükseklik modelini (SYM) seçerken doğruluğu, çözünürlüğü ve güncelliği göz önüne alınmıştır. Bu çalışmada; daha önce aynı çalışma sahasında SYM'lerle yapılan bölgesel analize göre yüksek doğruluklu sonuç veren SRTM1 modeli kullanılmıştır (Arl1 İl ve Abbak, 2017). SRTM1 modelinin global düşey doğruluğu $16 \mathrm{~m}$ olup yatay ve düşey datum olarak sirasiyla WGS84 elipsoidini ve EGM96 jeoidini referans alır. SRTM1 Modeli ücretsiz olarak web adresinden indirilmiştir (SRTM, 2018).

\subsubsection{GPS/Nivelman verileri}

GPS/Nivelman gözlemleri jeoit modellerinin değerlendirilmesinde ve geçerliliğinin kontrolünde sıça kullanılan veri kaynaklarıdır. Çalışma alanında yer alan Türkiye Ulusal Düşey Kontrol Ağ1 1999 (TUDKA99) birinci derece nivelman ağına bağlı ortometrik yükseklikleri bilinen 24 adet GPS/Nivelman noktasina ait veriler kontrol verisi olarak kullanılmıştır (Şekil2).

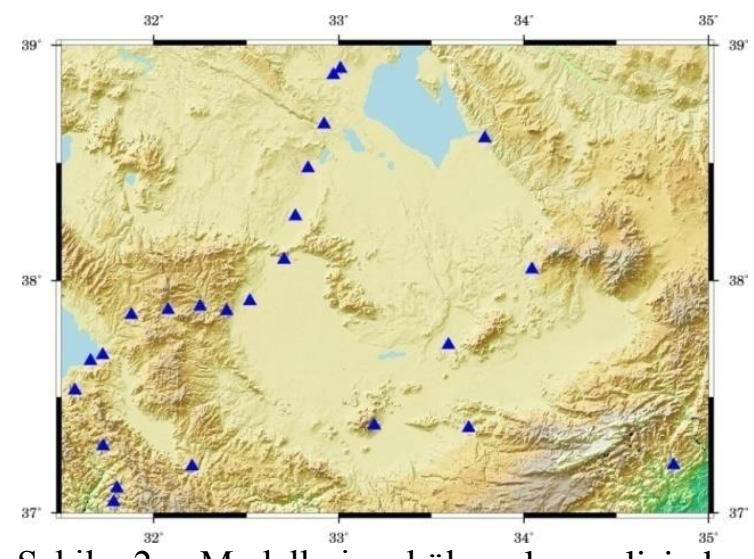

Şekil 2. Modellerin bölgesel analizinde kullanılacak GPS/Nivelman noktaları

Noktaların elipsoidal yüksekliklerinin doğruluğu $1-3 \mathrm{~cm}$, nivelmanla belirlenen ortometrik yüksekliklerinin doğruluğu $1-3$ $\mathrm{cm}$ civarında değişmektedir. Yüksek prezisyonlu iki ölçme tekniği yardımıyla belirlenen 24 adet GPS/Nivelman jeoit yüksekliğinin duyarlılığ $3 \mathrm{~cm}$ 'nin altındadır (Abbak, 2011; Üstün ve Demirel, 2006).

\section{SAYISAL UYGULMA}

\subsection{Global Yerpotansiyel Modellerin Bölgesel Analizi}

Global yerpotansiyel modellerin bölgesel doğruluğunun değerlendirilmesi amaciyla GPS/nivelman noktalarında, geometrik jeoit ondülasyonları hesaplanmıştır. Her model harm2und (Aydın Üstün tarafından geliştirilen) programında değerlendirilerek, modellerden jeoit ondülasyonlanı hesaplanmıştır. Hesaplanan jeoit ondülasyonu, GPS/Nivelman verilerinden elde edilen jeoit ondülasyonlarıyla karşılaştırılmıştır. Sayısal değerler doğrudan karşılaştırılmayıp, datum kayıklığ 1 ve uzun dalga boylu bileşenlerin etkisini barındırabileceği göz önünde bulundurularak 7 parametreli benzerlik dönüşümünden yararlanılmıştır. Dönüşüm sonucunda her bir model için, jeoit ondülasyonları arasındaki minimum, maksimum, ortalama ve karesel ortalama hata değerleri hesaplanmıştır (Tablo 2).

Tablo 2'ye göre Karesel Ortalama Hata $(\mathrm{KOH})$ değerlerinden de anlaşıldığı gibi global modelin açınım derecesi yükseldikçe GPS/Nivelman verileriyle uyumluluk artmaktadır. Sonuçlar incelendiğinde, en düşük doğruluğu CHAMP uydu verileri ile oluşturulan modeller göstermektedir. CHAMP uydusunun neredeyse 11 ylllik verisi mevcut olmasına rağmen modellerin doğruluğunda anlamlı bir iyileşme olmamıştır. GRACE uydu verileriyle oluşturulan modellere bakılırsa, oluşan modellerin doğruluğunda anlamlı bir artış göstermektedir. Ayrıca GRACE uydu verileri kullanılarak oluşturulmuş HUST-Grace2016s ve TongjiGRACE01 $\quad\left(\mathrm{N}_{\max }=160\right) \quad$ modellerine bakıldığında doğrulukları CHAMP uydu verileri ile oluşturulan modellere göre daha düşük doğruluk gösterirken, ITG-Grace2010s ve Tongji-Grace02s $\quad\left(\mathrm{N}_{\max }=180\right)$ modelleri CHAMP uydu verileri ile oluşturulan modellerle yaklaşık doğruluk göstermektedir. $\mathrm{Bu}$ durumun sebebi olarak GRACE uydu verileri yardımıyla global yerpotansiyel model elde edilirken kullanılan 160 açınım derecesinin yeterli olmadığ 1 değerlendirilmektedir. Bundan dolayı GRACE uydu verileri yardımıyla oluşturulacak global yerpotansiyellerin CHAMP uydu verileri ile elde edilen modellere göre doğruluğunun artması 
için, modellerde açınım derecesi olarak 180 derece ve üzeri kullanılması gerektiği sonucuna varılmıştır. CHAMP uydusu ve GRACE uydusu verileri bir arada kullanılarak oluşturulmuş GOCO01S modeline bakılırsa, modelin doğruluk derecesinde bir iyileşme görülmemiştir. Sadece son uydu misyonu GOCE uydusu modelleri irdelendiğinde diğer uyduların veri toplama süresinden daha kısa sürede topladığı verilerle en iyi sonuçları elde ettiği görülmektedir.

$\mathrm{Bu}$ sonuçlarda yeryuvarına en yakın uydu olması ve gelişen teknolojinin katkısı büyüktür. GRACE ve GOCE uydu verilerinin birleştirilerek oluşturulan modeller incelenirse, değerlendirme sonucu doğruluğu en yüksek modeller olarak ortaya çıkmıştır. Analiz sonuçlarına göre GOCE uydu verileriyle elde edilmiş GO_CONS_GCF_2_SPW_R4 yerpotansiyel modellinin doğruluğu $24.624 \mathrm{~cm}$, GRACE ve GOCE birleştirilmiş verilerinden oluşturulan doğruluğu ITU_GGC16 modelinin doğruluğu $21.441 \mathrm{~cm}$ olarak hesaplanmıştır.

ITU GGC16 modeli doğruluğu en yüksek model olarak belirlenmiştir. Seçilen modellerde GRACE verilerinin, oluşturulan birleşik modellerin doğruluğuna katkısı azda olsa görülmektedir.

Tablo 2. Güncel global yerpotansiyel modellerin GPS/nivelman verileriyle değerlendirilmesi [cm]

\begin{tabular}{llccccc}
\hline Model Ad1 & Veri kaynağ1 & $\mathrm{N}_{\max }$ & Min. & Max. & Ort & KOH \\
\hline ULux_CHAMP2013s & S(Champ) & 120 & -57.058 & 53.277 & -0.100 & 32.037 \\
EIGEN-CHAMP05S & S(Champ) & 150 & -57.79 & 59.656 & -0.014 & 31.819 \\
GOCO01S & S(Champ, Grace) & 224 & -57.658 & 61.491 & 0.001 & 32.094 \\
HUST-Grace2016s & S(Grace) & 160 & -63.702 & 70.929 & -0.016 & 39.447 \\
Tongji-GRACE01 & S(Grace) & 160 & -93.023 & 69.159 & 0.004 & 35.741 \\
ITG-Grace2010s & S(Grace) & 180 & -79.749 & 56.451 & 0.002 & 31.760 \\
Tongji-Grace02s & S(Grace) & 180 & -76.038 & 63.39 & 0.002 & 32.287 \\
JYY_GOCE04S & S(Goce) & 230 & -53.012 & 52.723 & 0.002 & 32.930 \\
IfE_GOCE05s & S(Goce) & 250 & -41.647 & 38.026 & 0.001 & 26.707 \\
GO_CONS_GCF_2_SPW_R4 & S(Goce) & 280 & -37.528 & 40.543 & 0.000 & 24.624 \\
GGM05G & S(Grace,Goce) & 240 & -43.519 & 51.507 & 0.000 & 27.585 \\
ITU_GGC16 & S(Grace,Goce) & 280 & -36.748 & 40.144 & 0.007 & $\mathbf{2 1 . 4 4 1}$ \\
\hline
\end{tabular}

\subsection{Global Yerpotansiyel Modellerin Bölgesel Jeoide Etkisi}

Yeryüzünden ölçülen gravite değerleri jeoit belirleme işleminde doğrudan kullanılmaz. $\mathrm{Bu}$ sebeple değerlerin gravite anomalilerine indirgenmesi gerekir. Jeoit çalışmalarında gravite anomalileri, boşlukta gravite anomalisi ve Bouguer anomalisi olarak iki başlık altında incelenir. Boşlukta gravite anomalisi $\Delta g_{F A}$, yeryüzünde bir noktada ölçülen gravite değeri ile normal gravite arasındaki farktır ve

$\Delta g_{F A}=g_{P}-\gamma_{Q}$

eşitliği ile hesaplanır. Ancak bir noktanın boşlukta gravite anomalisi yeryuvarının topografyasından oldukça etkilenmektedir.
Diğer yandan gridleme işlemini gerçekleştirmek için boşlukta gravite anomalilerinin barındırdığı topografya etkisini en aza indirmek gerekmektedir. Bunun için en pratik yöntem topografyayı sabit yoğunluklu kabul etmektir. Bahsedilen yöntem literatürde basit Bouguer yaklaşımı olarak bilinir ve;

$\Delta g_{S B}=\Delta g_{F A}-2 \pi G \rho H$

eşitliğiyle gösterilir. Burada $G$ Newton'un evrensel çekim sabitini, $\rho$ Bouguer plakasının yoğunluğunu $\left(2670 \mathrm{~kg} / \mathrm{m}^{3}\right), \quad H$ ise yersel gravite gözlemlerinin ortometrik yüksekliğini ifade eder. Bouguer anomalileri kullanılarak oluşturulan yüzey, boşlukta gravite anomalileri ile oluşturulan yüzeye göre daha yumuşak bir yüzeydir ve enterpolasyon işlemi için daha elverişlidir. 
Bir sonraki aşama gridleme işlemidir. Dağınık halde bulunan gravite verilerinin grid merkezine taşınması gerekmektedir ve grid merkezinin yüksekliğine ihtiyaç vardır. İhtiyaç duyulan yükseklikler sayısal yükseklik modelinden (SRTM1 modeli) elde edilmiştir. Dağınık gravite verileri basit Bouguer yaklaşımı ile değerlendirilmiş, en yakın komşu enterpolasyon tekniği ile grid merkezine taşınmıştır. Böylece grid merkezlerinde Bouguer anomalileri elde edilmiştir. SRTM1 yükseklik modelinden yararlanarak grid merkezlerinde $0.02^{\circ} \times 0.02^{\circ}$ çözünürlüklü yükseklikler hesaplanmıştır. Hesaplanan yükseklik değerlerine göre Bouguer katmanının etkisi elde edilmiş, grid merkezlerine taşınan Bouguer anomalilerine eklenerek yine grid merkezlerinde boşlukta gravite anomalisi üretilmiştir (Abbak vd. 2012).

Global yerpotansiyel modeller gravite anomalisi, jeoit ondülasyonu ve çekül sapması gibi büyüklüklerin hesaplanabildiği, yeryuvarının çekim alanını tanımlayan katsayılardır. $\mathrm{Bu}$ modellerden jeoit ondülasyonu,

$N(\theta, \lambda, r)=$

$\frac{G M}{R}\left[\sum_{n=0}^{N_{\max }}\left(\frac{a}{r}\right)^{n+1} \sum_{m=0}^{n}\left(\bar{C}_{n m} \cos m \lambda+\right.\right.$

$\left.\left.\bar{S}_{n m} \sin m \lambda\right) \bar{P}_{n m} \cos (\theta)\right]$

boşlukta gravite anomalileri;

$\Delta g_{F A}(\theta, \lambda, r)=$

$\frac{G M}{r^{2}}\left[\sum_{n=2}^{N_{\max }}\left(\frac{a}{r}\right)^{n} \sum_{m=0}^{n}\left(\bar{C}_{n m} \cos m \lambda+\right.\right.$

$\left.\left.\bar{S}_{n m} \sin m \lambda\right) \bar{P}_{n m} \cos (\theta)\right]$

eşitlikleri yardımıyla hesaplanır. $\bar{C}_{n m}, \bar{S}_{n m} n$ derece $m$ sıradaki tam normalleştirilmiş küresel harmonik katsayıları; $(\theta, \lambda, r)$ küresel

karş1 enlemi, boylamı, jeosentrik yarıçap1; $\bar{P}_{n m}$, normalleştirilmiş bütünleşik Legendre fonksiyonunu gösterir.

Yersel gravite verilerinin bulunduğu alan dışında integrasyona katılacak gravite verileri EGM2008 modelinden türetilmiştir. EGM2008 modeli diğer global yerpotansiyel modellerine göre daha fazla veri kaynăg 1 içermekte ve açınım derecesi yüksek olduğundan daha yüksek doğruluklar sunar. $\mathrm{Bu}$ çalışmada jeoit modellerini üretmek için
LSMSSOFT programı kullanılmıştır (Abbak ve Üstün, 2015). Seçilen her bir güncel global yerpotansiyel ile ayrı ayrı bölgesel jeoit modelleri oluşturulmuştur. KTH tekniğinde kullanılan modifikasyon parametreleri olan, integrasyon yarıçapı $\left(\varphi_{0}\right)$, yersel verilerin varyans1 $\left(\sigma_{\Delta g}\right)$ ve global yerpotansiyel modellerden üretilen uzun dalga boylu bileşenlerin maksimum açınım derecesinin $(L)$ belirlenmesinde literatürde kesin bir yöntem yoktur. $\mathrm{Bu}$ parametrelerin belirlenmesinde deneme ve yanılma yöntemi kullanılmışırır. İntegrasyon yarıçapı, çalışma alanına yakın alanlarda bürokratik ve ekonomik sebeplerden kaynaklı yersel gravite gözlemlerinin bulunmaması ve çalışma alanının büyüklüğü göz önüne alınarak, $0.5^{\circ}, 0.75^{\circ}$ ve $1^{\circ}$ değerleri kullanılarak her model için hesaplamalar yapılmış ve tüm modeller için optimal sonuç veren $0.5^{\circ}$ değeri seçilmiştir. Yersel gravite verilerinin standart sapmas1 Abbak (2011) tarafindan $7 \mathrm{mGal}$ olarak belirlendiğinden bu uygulamada da aynı değer hesaplamalarda kullanılmıştır. Global yerpotansiyel modellerden türetilen uzun dalga boylu bileşenler 90 ile 220 dereceler arasında her bir model için denenmiştir. Seçilen her model için optimal sonuçları veren bu katsayı, sadece CHAMP uydu verilerinden elde edilen yerpotansiyel modeller için 180 derece, diğer yerpotansiyel modeller için ise 120 ya da 130 derece olarak belirlenmiştir.

Son olarak oluşturulan 12 adet jeoit modelleri, GPS/Nivelman ile 7 parametreli benzerlik dönüşümünden yararlanarak karesel ortalama hataları hesaplanmıştır (Tablo 3). 
Tablo 3. Bölgesel jeoit modellerinin GPS/nivelman verileriyle değerlendirilmesi [cm]

\begin{tabular}{llcccccc}
\hline Global Model Ad1 & Veri kaynağ1 & $\mathrm{N}_{\max }$ & $\mathrm{L}$ & Min. & Max. & Ort & KOH \\
\hline ULux_CHAMP2013s & S(Champ) & 120 & 180 & -11.514 & 20.758 & -0.030 & 7.500 \\
EIGEN-CHAMP05S & S(Champ) & 150 & 180 & -13.583 & 17.782 & -0.004 & 8.422 \\
GOCO01S & S(Champ, Grace) & 224 & 120 & -10.766 & 17.245 & -0.089 & 6.869 \\
HUST-Grace2016s & S(Grace) & 160 & 120 & -10.764 & 17.096 & -0.117 & 6.877 \\
Tongji-GRACE01 & S(Grace) & 160 & 130 & -11.345 & 17.723 & -0.058 & 6.823 \\
ITG-Grace2010s & S(Grace) & 180 & 120 & -10.756 & 17.308 & -0.035 & 6.879 \\
Tongji-Grace02s & S(Grace) & 180 & 120 & -10.748 & 17.297 & -0.045 & $\mathbf{6 . 7 8 0}$ \\
JYY_GOCE04S & S(Goce) & 230 & 120 & -10.708 & 17.301 & -0.029 & 6.869 \\
IfE_GOCE05s & S(Goce) & 250 & 120 & -10.696 & 17.242 & -0.039 & 6.870 \\
GO_CONS_GCF_2_SPW_R4 & S(Goce) & 280 & 130 & -11.556 & 18.032 & -0.035 & 6.866 \\
GGM05G & S(Grace,Goce) & 240 & 120 & -10.809 & 17.581 & 0.022 & 6.862 \\
ITU_GGC16 & S(Grace,Goce) & 280 & 130 & -11.587 & 18.004 & -0.063 & 6.867 \\
\hline
\end{tabular}

Sonuçlar incelendiğinde; CHAMP yer potansiyel modelleri kullanilarak oluşturulmuş jeoit modelleri en düşük doğruluğu göstermektedir. CHAMP modelleri, jeoit belirleme işleminde beklenilen doğruluğu sağlamadığından güncelliğini kaybetmiştir. GRACE ve GOCE uyduları yardımıyla oluşturulan global yerpotansiyel modellerden elde edilen jeoit modellerinin doğruluğu ise yaklaşı $\pm 6.8 \mathrm{~cm}$ olarak hesaplanmıştır. Buna bağ 11 olarak jeoit yüzeyi belirlerken doğruluğu değiştiren ve etkileyen asıl faktörün yersel gravite verilerinin kalitesi olduğu sonucuna varılmıştır. Jeoit modellemesi yapılacak bölgelerde yersel gravite verileri yüksek prezisyonlu ve yeterli yoğunlukta elde edilmesi gerekmektedir.

\section{SONUÇLAR ve TARTIŞMA}

$\mathrm{Bu}$ çalışmada ilk olarak uydu misyonlarıyla elde edilen yeryuvarı gravite alanı verilerinden üretilen ULux_CHAMP2013s, EIGEN-CHAMP05S, GOCO01S, HUSTGrace2016s, Tongi-GRACE01, ITGGrace2010s, Tongji-Grace02s, JYY_GOCE04S, IIfE_GOCE05s, GO_CONS_GCF_2_SPW_R4, GGM05G, ITU_GGC16 güncel global yerpotansiyel modellerinin bölgesel doğrulukları test edilmiştir. Yapılan testler sonucunda bölgesel ya da ulusal olarak jeoit belirleyebilmek için en uygun global yerpotansiyel modeli belirlenmeye çalışılmıştır. Bu amaçla seçilen farklı açınım derecelerine sahip uydu bazlı global yerpotansiyel modellerinden türetilen jeoit ondülasyonları, GPS/Nivelman verilerinden hesaplanan jeoit ondülasyonları ile karşılaştırılmıştır.

CHAMP uydusu ilk çıktığı zamanlar iyi sonuçlar verdiği düşünülürken; bu uydunun uzun yıllar boyunca elde ettiği veriler, yeryuvarının gravite alanını belirlemede anlamlı iyileşmeler gösterememiş ve yerini gelişen teknoloji sayesinde üretilen GRACE ve GOCE uydu verilerine bırakmıştır. Seçilen GRACE uydu verileri ile üretilen HUSTGrace2016s, Tongji-GRACE01, ITGGrace2010s, Tongji-Grace02s, modellerinin bölgesel doğrulukları incelendiğinde; CHAMP uydu verileri ile elde edilen ULux_CHAMP2013s, EIGEN-CHAMP05S modellerine göre iyileşme gösteren modeller olarak görülmemiştir. Bu duruma sebep olarak GRACE uydu verileri ile global yerpotansiyel modelleri elde edilirken kullanılan açınım derecelerinin bu uydu verileri için yetersiz kalmış olabileceği düşünülmektedir. Diğer bir ifadeyle GRACE uydu verileri ile global bir yerpotansiyel modeli oluşturulurken minimum açınım derecesi olarak 180 derece olarak çözüm gerçekleştirilmelidir denebilir. GOCE uydu verileriyle elde edilen modeller CHAMP ve GRACE uydu verileri ile elde edilen modellere göre daha yüksek doğruluk göstermektedir. Ancak GOCE ve GRACE uydu verilerinin bir arada kullanılmasıyla elde edilen modeller en başarılı sonucu vermiştir. GOCE uydu verilerinin bölgesel doğrulukları yüksek iken GRACE uydu verilerinin çözüme 
dahil edilmesi az da olsa model doğruluklarının iyileşmesine sebep olmuştur. Bilim ve teknolojinin gelişmesiyle birlikte, gravite alanı belirleme amaçlı son uydu olan GOCE gravite alanının uzun dalga boylu bileşenlerinin belirlenmesinde yüksek doğruluk sağladığı anlaşılmaktadır. Seçilen modeller içerisinde bölgesel doğruluğu en yüksek model GRACE ve GOCE uydu verilerinin birleştirilmesiyle elde edilen ITU GGC16 modeli olarak tespit edilmiştir.

İkinci aşamada yakın yer uyduları olan CHAMP, GRACE ve GOCE uyduları ile elde edilerek oluşturulmuş 12 adet global yerpotansiyel modeli ile KTH tekniğinden yararlanarak Konya Kapalı Havzasında bölgesel jeoit modelleri oluşturulmuştur. Oluşturulan her jeoit yüzeyi GPS/Nivelman verileri ile elde edilen jeoit yüzeyi ile 7 parametreli benzerlik dönüşümünden yararlanarak karesel ortalama hataları hesaplanıp karşılaştırılmıştır.

Karşılaştırma sonuçlarına göre, CHAMP uydu verileri ile oluşturulan modellerin güncelliğini kaybettiği ve beklenilen doğrulukta bir jeoit belirlemek için yetersiz kaldığ gözlemlenmiştir. GRACE ve GOCE uydu verileriyle belirlenen tüm modellerin doğruluğu yaklaşık $\pm 6.8 \mathrm{~cm}$ hesaplanmıştır. GRACE uydu verileri ile elde edilen ve bölgesel olarak doğruluğu düşük doğruluklu modeller dahil benzer sonuçlar görülmüştür. Jeoit modelleme işleminde, her ne kadar global yerpotansiyel modellerin bölgesel doğrulukları fazla olsa dahi jeoit modeli üzerinde kayda değer bir iyileșme sağlamamıştır. Bundan dolayı jeoit yüzeyi belirlerken doğruluğu değiştiren ve etkileyen asıl faktörün yersel gravite verilerinin kalitesi olduğu sonucuna ulaştırmıştır. Jeoit modellemesi yapılacak bölgelerde yersel gravite verileri yüksek prezisyonlu ve yeterli yoğunlukta elde edilmesi gerekmektedir.

\section{KAYNAKÇA}

Abbak, R. A. (2011). Global Yerpotansiyel Modellerinin Spektral Yöntemlerle Değerlendirilmesi ve Jeoit Belirleme İçin Yerel Olarak İyileştirilmesi, Doktora Tezi, Selçuk Üniversitesi, Konya.

Abbak, R. A. (2017). Fiziksel Jeodezi: Teori ve Uygulama, Atlas Akademi, Konya.
Abbak, R. A. ve Ustun, A. (2015). A software package for computing a regional gravimetric geoid model bythe KTH method, Earth Science Informatics, 8(1),255-265.

Abbak, R. A., Üstün, A. ve Ellmann, A. (2012). Ortalama Gravite Anomalilerinin Enterpolasyon Basit ve Tamamlanmış Bouger Yaklaşımının Karşılaştırılması, Jeodezi ve Jeoinformasyon Dergisi, 1(1), 45-52.

Akyilmaz, O., Ustun, A., Aydin, C. Arslan, N., Doganalp, S., Guney, C., Mercan, H., Uygur, S.O., Uz, M.,Yagci,O. 2016, ITU_GGC16 The combined Global gravity field Model including GRACE \& GOCE data up to degree and order 280; GFZ Data Services; http://doi.org/10.5880/icgem.2016.005 Erisim tarihi: 05.03.2018

Al-Krargy, E., Hosny, M., and Dawod, G., (2015), Investigating the Precision of Recent Global Geoid Models and Global Digital Elevation Models for Geoid Modelling in Egypt. Regional Conference on Surveying \& Development, Sharm El-Sheikh, Egypt, 3-6 October 2015.

Arlı İl, H. T. ve Abbak, R. A. (2017). Accuracy Analysis of ASTER and SRTM Digital Elevation Models: A Case Study In Turkey. 17th International Multidisciplinary Scientific Geoconference SGEM, Bulgaria

Bettadpur, S. et al, 2015 Evaluation of the GGM05 Mean Earth Gravity models, Geophysical Research Abstracts, Vol. 17, EGU2015-4153, 2015, Vienna, Austria

CHAMP. (2018). CHAllenging Minisatellite Payload http://op.gfz-potsdam.de/champ/

Chen, Q. et al, 2016 An improved GRACE monthly gravity field solution by modelling the non-conservative acceleration and attitude observation errors, Journal of Geodesy, 90(6), 503523.

Doganalp, S. (2016). An Evaluation of Recent Global Geopotential Models for Strip Area Project in Turkey. Earth Sciences Research Journal, 20(3), C1-C10.

Ellmann, A. Ve Sjöberg, L. E. (2004) Ellipsoidal correction for the modified Stokes' formula. Boll. Geod.Sci.Aff., 63,153-172.

Erol, B., Çelik, R. N. ve Sideris, M. G. (2008). Güncel Global Potansiyel Modellerin Yersel Veriler ile Test Edilmesi. ITÜ Dergisi, 7(6), 47-58.

Erol, B., Sideris, M. G. ve Çelik, R. N. (2009). Comparison of global geopotential models from the champ and grace missions for regional geoid modelling in Turkey. 
Studia Geophysica et Geodaetica, 53(4), 419-441

Flechtner, F. et al (2010) The Release 04 CHAMP and GRACE EIGEN Gravity Field Models; Springer, p. 41-58, Berlin.

Gatti, A., Reguzzoni, M., Migliaccio, F., Sanso, F. (2014) Space-wise grids of gravity gradients from GOCE data at nominal satellite altitude Paris.

GOCE. (2018).Gravity field and steady-state Ocean Circulation Explorer. http://www.esa.int/Our_Activities/Observi ng_the_Earth/GOCE Erişim tarihi: 05.03.2018.

GRACE. (2018). Gravity Recovery and Climate Experiment.

http://www.csr.utexas.edu/grace Erişim tarihi: 05.03.2018

Heiskanen, W. A. ve Moritz H. (1967). Physical Geodesy, W. H. Freeman and Co., London, U.K.

ICGEM. (2018). Internternational Centrefor Global Earth Models (ICGEM). http://icgem.gfzpotsdam.de/ICGEM/ Erişim tarihi: 05.03.2018

Kiamehr R., 2006. Precise Gravimetric Geoid Model for Iran Based on GRACE and SRTM Data and the Least-Squares Modification of Stokes' Formula with Some Geodynamic Interpretations. Ph.D. Thesis, Division of Geodesy, Royal Institute of Technology, Stockholm, Sweden.

Mayer-Gürr, T., Kurtenbach, E., Eicker, A. (2010) ITG-Grace2010 Gravity Field Model; http://www.igg.unibonn.delapmg/index.ph p?id=itg-grace2010 Erişim tarihi: 05.03 .2018

Pail, R. et al, 2010 Combined satellite gravity field model GOCO01S derived from GOCE and GRACE; Geophysical Research Letters, 37(20)

Shen, Y., Chen, Q., Hsu, H., Zhang, X., Lou, L. (2013) A modified short arc approach for recovering gravity field model; Austin, TX, 2013

Sjöberg, L E. (2003a) A compultational scheme to model geoid by the modified Stokes Formula without gravity reductions, Journal of Geodesy, 77, 423-432.

Sjöberg, L E. (2003b) A general model for modifying Stokes' formula and its leastsquares solution, Journal of Geodesy, 77, 459-464.

Sjöberg, LE. (2003c) A solution to the downward continuation effect on the geoid determination by Stokes' Formula. Journal of Geodesy, 77:94-100.
SRTM (2018) Shuttle Radar Topography Mission. http://www2.jpl.nasa.gov/srtm Erişim tarihi: 05.03.2018.

Ulotu P.E., 2009. Geoid Model of Tanzania from Sparse and Varying Gravity Data Density by the KTH Method. PhD. Thesis. Division of Geodesy, Royal Institute of Technology (KTH), Stockholm, Sweden.

Üstün, A. ve Demirel, H. (2006). Long-Range Geoidt esting by GPS-Leveling Data in Turkey. Journal of Surveying Engineering, 132(1), 15-23

Yi, Weiyong, Rummel, Reiner, Gruber, Thomas. (2013) Gravity field contribution analysis of GOCE gravitational gradient components; Studia Geophysica et Geodaetica, 57(2), 174-202

Weigelt, M., van Dam, T., Jäggi, A., Prange, L., Tourian, M. J., Keller, W., Sneeuw, N. (2013) Time-variable gravity signal in Greenland revealed by high-low satelliteto-satellite tracking, Journal of Geophysical Research, 118(7), 3848-3859.

Wu, H., Müller, J., and Brieden. (2017) The IfE global gravity field model from GOCEonly observations, International Symposium on Gravity, Geoid and Height Systems, 19-23 September 2016, Thessaloniki, Greece.

Zhou, H., Luo, Z, Zhou, Z., Li, Q., Zhong, B., Hsu, H. (2016) A new time series of GRACE monthly gravity field models: HUST-Grace2016; GFZ Data Services; http://doi.org/10.5880/ICGEM.2 016.0 Erișim tarihi: 05.03.2018 